\title{
Effect of Hot Air Thin Layer Drying Temperature on Physicochemical and Textural Properties of Dried Horseradish
}

\author{
Pranabendu Mitra (Corresponding Author) \\ Department of Food and Nutrition, University of Wisconsin-Stout \\ $41510^{\text {th }}$ Avenue East, Menomonie, WI, 54751, USA \\ Tel: 1-751-232-5332_Email: mitrap@uwstout.edu
}

\begin{abstract}
Md. Abdul Alim
Department of Food Technology and Rural Industries, Bangladesh Agricultural University, Mymensingh 2202, Bangladesh
\end{abstract}

Venkatesh Meda

Department of Chemical and Biological Engineering, University of Saskatchewan

57 Campus Drive, Saskatoon, SK, S7N5A9, Canada

Received: September 29, 2019 Accepted: October 26, 2019 Published: October 28, 2019

doi:10.5296/jfi.v3i1.15721ＵRL: http://dx.doi.org/10.5296/jfi.v3i1.15721

\begin{abstract}
The horseradish (Armoracia rusticana) is an important crop as ingredients for many commercial food products and medicinal uses. However, the horseradish is perishable and preservation of this crop for supplying year-round is necessary. Drying can be used to preserve the horseradish but establishing a suitable drying method and conditions are important for product quality of dried horseradish. The objective of this study was to investigate the effects of hot air-drying temperatures on the physicochemical and textural properties of dried horseradish samples to determine the appropriate hot air-drying conditions. The sliced horseradish samples were dried at 55, 65, 75, 85 and $95{ }^{\circ} \mathrm{C}$ using a conventional hot air drier. The physicochemical and textural properties of the dried horseradish samples
\end{abstract}




\section{Macrothink}

were determined, and the results were compared for different drying temperatures. The ANOVA analysis indicated that the drying temperature affected the physicochemical and textural properties of dried horseradish samples significantly $(\mathrm{p}<0.05)$. The experimental results indicated that the moisture content $(9.18-6.15 \%, w b), a_{w}(0.06-0.03)$, porosity (31.47-12.13\%) and rehydration ratio (82.74 -44.47\%) decreased and piece density (0.63-0.84 $\mathrm{g} / \mathrm{mL})$, hardness $(193.63-298.31 \mathrm{~N})$, cohesiveness (1.04-1.32), gumminess (202.13-390.12) and chewiness (635.08-1223.55) of dried horseradish samples increased with the drying temperature. Power law model indicated that the porosity was linearly corelated to the rehydration ratio of dried horseradish samples. The overall results revealed that relatively lower $\left(55-65{ }^{\circ} \mathrm{C}\right)$ drying temperature range was suitable to keep the quality of the dried horseradish samples. The findings of this study are expected to be helpful for the commercial drying of horseradish samples using hot air-drying method.

Keywords: Horseradish preservation, hot air-drying, thin layer drying, physicochemical and textural properties, power law model

\section{Introduction}

The use of horseradish (Armoracia rusticana) can be traced back to 1500 B.C. where the Egyptians and early Greeks used this for medical purposes. They made horseradish paste to cure body pains and arthritis and syrup to cure anything for the common cold to tuberculosis (Agneta, Möllers, \& Rivelli, 2013; Nguyen, Gonda, \& Vasas, 2013). Other cultures like the Jews gridded horseradish into a spice to use for religious reasons during Passover (Agneta et al., 2013). Today, the horseradish is mostly consumed in sauce form as a condiment on anything from meats, potatoes, and different vegetables (Agneta et al., 2013; Andruţa, Vlaic, Petruț, Chiș, \& Muste, 2017; Lin, Preston, \& Wei, 2000; Nguyen et al., 2013). The horseradish has a fair amount of heat in it and is comparable to a habanero pepper of the Scoville Scale. This heat comes from the compound allyl isothiocyanate (AITC). Studies have reported that AITC can be helpful for cancer prevention and can rapidly induce cancer cell's death (Agneta et al., 2013; Lin et al., 2000; Nguyen et al., 2013). The horseradish has also been reported to have antimicrobial, spasmolytic, cytotoxic, antiseptic, diuretic, stimulant, and antioxidant properties. The horseradish can also be used as a mild antibiotic that can relieve urinary infections and sinus infections (Agneta et al., 2013; Nguyen et al., 2013). Although there is not a large demand for the horseradish root for individuals, there is a substantial demand for products that use horseradish. About 24 million pounds/year of horseradish roots are processed in the Unites States of America and Silver Spring Gardens (a country's leading horseradish processor) alone processed about 6 million gallons/year horseradish to produce different kinds of sauces and other condiments (Kumar, 2003). However, horseradish is a high perishable crop due to high moisture content in it and the shelf-life of this horseradish is very short at room temperature $\left(20^{\circ} \mathrm{C}\right)$. So, refrigeration or freezing for longer storage is necessary to preserve the horseradish. This existing preservation process is inconvenient and not cost effective. The economically viable potential preservation method is needed to preserve and extend the shelf-life of horseradish. Drying of horseradish can increase the shelf-life, makes them easier to store and transport, and offers accessibility all year long. 


\section{Macrothink}

Drying can be defined as a method of safely reducing the moisture content of products to minimize the deterioration of products to increase the shelf-life of the products, subsequently, increase profits (Babu, Kumaresan, Raj, \& Velraj, 2018; Mitra, Meda, \& Green, 2013; Shende \& Datta, 2019). There are many methods of drying including but not limited to freeze drying, microwave-vacuum drying, vacuum drying and hot air drying. In theory all these practices dry a product, however, not all the drying methods work well with all products (Babu et al., 2018; Mitra et al., 2013; Shende \& Datta, 2019). The most frequently used conventional drying method is hot air drying, this is because it is fairly cost effective at the commercial level (Babu et al., 2018; Mitra et al., 2013). In this process, the surface of the product is exposed to hot air and then the heat transfers from the surface throughout the products. The products are placed in a hot air drier for a substantial amount of time at a high temperature. The drying temperature effects of how much water can be removed from a product. Also, the higher drying temperature reduces the drying time, but affects the quality of the products significantly. If materials are exposed to air in the drier for a longer time, enzymatic and non-enzymatic browning reactions may occur. Furthermore, all drying systems are not equally effective to retain the valuable compounds in horseradish that given them there many health benefits. Therefore, it is important to identify an effective and economically viable drying method to retain quality and maximum health benefits of horseradish. For this study, we chose to use hot air-drying method because it is relatively affordable for fruits and vegetables drying on a commercial level. It also reduces the size of the product making it easier to store and transport. The objective of this research was to investigate the effects of hot air thin layer drying temperatures on the physicochemical and textural properties of dried horseradish samples.

\section{Materials and Method}

\subsection{Materials}

Fresh horseradish (Armoracia rusticana) roots were collected from the Huntsinger Farms Inc., Eau Claire, WI, USA. The horseradish roots were cleaned under running water to remove the surface foreign materials or impurities. The cleaned horseradish roots were peeled with a hand peeler and were sliced into $1 \mathrm{~mm}^{3}$ in size with a mechanical slicer. The sliced horseradish roots were used for hot air thin layer (single layer) drying. 


\section{$\triangle$ Macrothink}

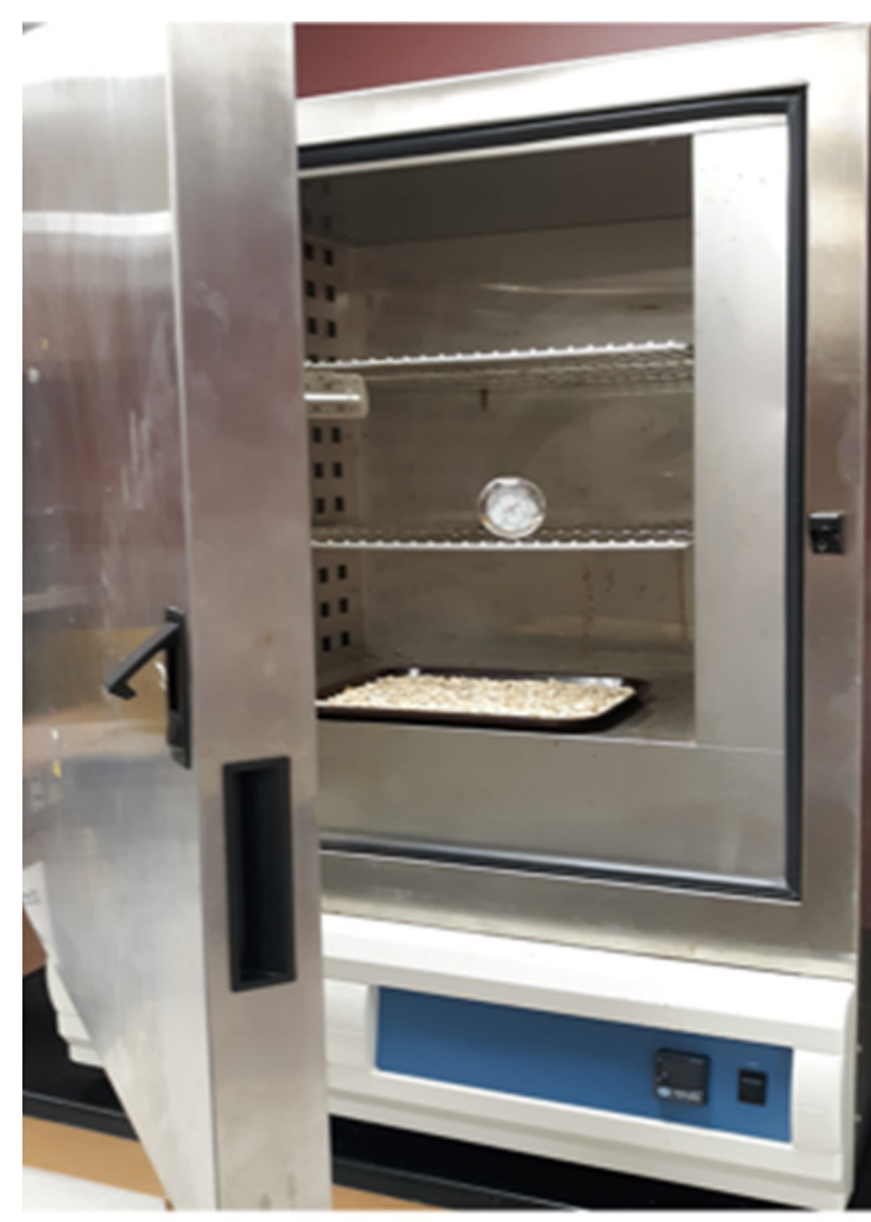

Convective hot air-drier used in this study

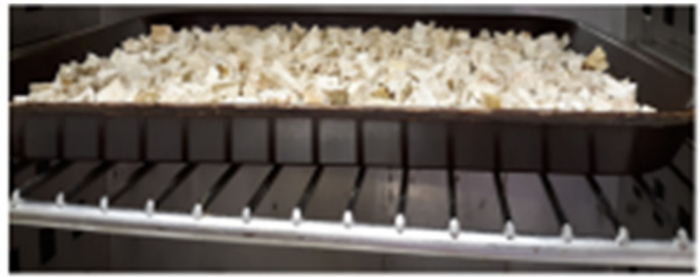

Sliced horseradish in a thin layer drying tray
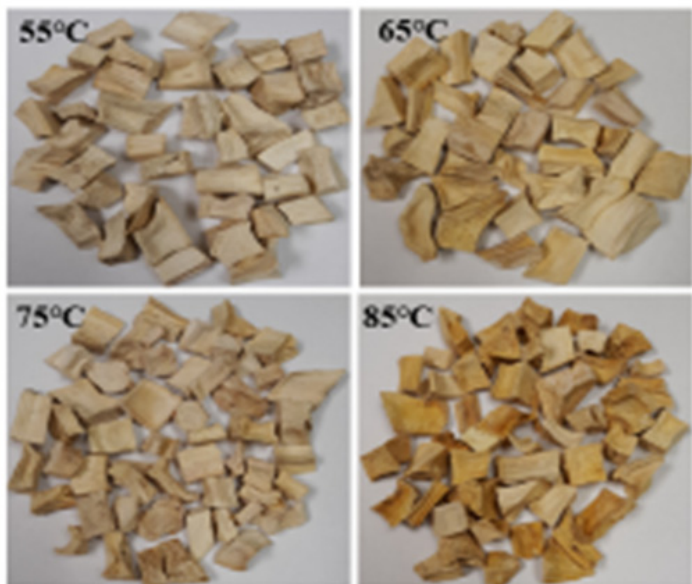

$85^{\circ} \mathrm{C}$

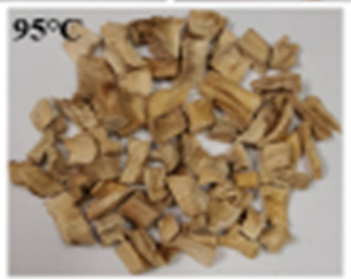

Horseradish dried at different temperatures

Figure 1. A convective hot air-drier and horseradish samples dried at 55, 65, 75, 85 and $95{ }^{\circ} \mathrm{C}$

\subsection{Hot Air Thing Layer Drying of Horseradish}

The horseradish slices were spread into an aluminum tray in a single layer (thin layer) and minimized the overlapping of the slices in the tray to ensure single layer distribution of the slices. The tray with sliced horseradish was placed in a convective hot air dryer (Lindberg/Blue M drier, model: MO 1450SA-1, USA) as shown in Figure 1, and dried at 55, $65,75,85$ and $95^{\circ} \mathrm{C}$ with a constant air velocity of $1.2 \mathrm{~m} / \mathrm{s}$ until the dried horseradish reached to a constant weight. The weights of the tray with samples were measured periodically and the drying end point was determined when three consecutive weights were constant during drying. The total drying time was in the range of 8-15 hours depending on the drying temperature. The dried samples were cooled to room temperature and packed in a polyethylene bag for the physicochemical and textural analysis.

\subsection{Physicochemical Characterization of Dried Horseradish}

\subsubsection{Determination of Moisture Content}

Ten grams $(10 \mathrm{~g})$ of a sample were dried at $140{ }^{\circ} \mathrm{C}$ for 2 hours in a convective oven dryer and 
were transferred to a desiccator after drying and weighed soon after reaching to the room temperature. The moisture content of each sample was determined in duplicate. The percentage of moisture content (wb) was determined using the following equation.

$$
\% \text { Moisture content }(\mathrm{wb})=\frac{\text { Mass of water of the product }}{\text { Total mass of the product }} \times 100
$$

\subsubsection{Determination of Water Activity $\left(\mathrm{a}_{\mathrm{w}}\right)$}

Water activity $\left(\mathrm{a}_{\mathrm{w}}\right)$ of the dried horseradish was determined using an AQUA-LAB ${ }^{\mathrm{TM}}$ Dew point 4TE DUO (Corona, CA) water activity meter. Two replications for each sample was conducted and the average value of the water activity was reported.

\subsubsection{Determination of Bulk Density}

Ten grams $(10 \mathrm{~g})$ of the dried horseradish were poured into a $100 \mathrm{~mL}$ graduated cylinder. The edge of the cylinder was tapped repeatedly until the samples came to a completely settled place. The volume (bulk volume) was then recorded. The bulk density was calculated using the flowing equation. This process was repeated two times to obtain an average bulk density of the dried horseradish.

$$
\text { Bulk Density }\left(\frac{g}{m L}\right)=\frac{\text { Mass of dried horseradish }(g)}{\text { Bulk vloume of dried horseradish }(m L)}
$$

\subsubsection{Determination of Piece Density}

The piece volume of the dried horseradish was determined using the rapeseed displacement method (AACC, 2001). $10 \mathrm{~g}$ of dried horseradish was placed into a $100 \mathrm{~mL}$ of graduated cylinder. Then the cylinder was filled to the $100 \mathrm{~mL}$ line with the rapeseeds by tapping repeatedly until the samples came to a completely settled place. The dried horseradish and the rapeseeds were taken out from the cylinder and was separated the rapeseeds from the dried samples. The separated rapeseeds were again placed into the cylinder and tapped to complete settlement. The volume of the rapeseeds was measured. The volume (piece volume) of the dried horseradish was calculated by subtracting the volume of rapeseeds from the volume of graduated cylinder $(100 \mathrm{~mL})$. The piece density was calculated using the following equation. Two replications were conducted, and the average value of piece density was reported.

$$
\text { Piece Density }\left(\frac{g}{m L}\right)=\frac{\text { Mass of dried horseradish }(g)}{\text { Volume of dried horseradish }(m L)}
$$

\subsubsection{Determination of Solid Density}

The dried horseradish samples were ground, and the ground powder was sieved through a 60-mesh sieve. A $10 \mathrm{~mL}$ graduated cylinder was filled with 5 grams of 60-mesh sieved dried horseradish powder. The edge of the cylinder was tapped repeatedly until the samples came to a completely settled place. The volume (solid volume) of the completely settled samples in the cylinder were measured. Two replications were conducted for the solid density. The solid density was determined using the following equation. 


$$
=\frac{\text { Solid density }\left(\frac{g}{m L}\right)}{\text { Mass of } 60-\text { mesh sieved ground horseradish powder }(\mathrm{g})}
$$

\subsubsection{Determination of Porosity}

The porosity (\%) of dried horseradish samples was calculated using the following equation based on piece density and solid density of the dried horseradish samples.

$$
\text { Porosity }(\%)=\frac{\text { Solid density of samples }- \text { Piece density of samples }}{\text { Solid density of samples }} \times 100
$$

\subsubsection{Determination of Rehydration Ratio}

Twenty-five grams ( $25 \mathrm{~g}$ ) of dried horseradish were submerged into $500 \mathrm{~mL}$ of distilled water for an hour at $20^{\circ} \mathrm{C}$. The rehydrated dried horseradish was weighted. The rehydration ratio (\%) of dried horseradish was determined using the flowing equation. The rehydration experiment of each sample was performed in duplicate.

$$
=\frac{\begin{array}{c}
\text { Rehydration ratio } \\
\text { Rehydrated weigh of samples }- \text { Initial weight of samples }
\end{array}}{\text { Initial weight of samples }} \times 100
$$

\subsubsection{Determination of Color}

A Hunter Lab ColorFlex ${ }^{\mathrm{TM}}$ Colorimeter (Hunter Associates Laboratory Inc., Reston, Virginia, USA) was used to determine the color profile of horseradish. The Hunter L value (lightness/darkness), a value (redness/greenness) and b value (yellowness/blueness) were determined. Color measurement of horseradish was performed in six replicates.

\subsubsection{Textural Characterization of Dried Horseradish}

The textural profile (hardness, cohesiveness, springiness, gumminess and chewiness) of horseradish samples dried at 55, 65, 75, 85 and $95{ }^{\circ} \mathrm{C}$ was determined using a two-cycle compression test (Bourne, 2002; Nagalakshmi, Mitra, \& Meda, 2014) with an Instron Machine (Instron Corporation, Norwood, USA). The dried horseradish samples were placed on the lower ram and the upper ram with a $35 \mathrm{~mm}$ stainless steel probe attached with a $500 \mathrm{~N}$ load cell was used to compress the dried samples with a test speed of $1 \mathrm{~mm} / \mathrm{s}$ to break to $80 \%$ strain of the samples. Before starting the compression test, the anvil height of the probe was adjusted to 1-1.5 $\mathrm{mm}$ depending on the height of the tested samples. A two-cycle force-deformation curve was generated using the Bluehill 3 software to determine the textural properties of dried horseradish. The maximum force required to attain a given deformation was calculated as hardness $(\mathrm{N})$ of the samples. Cohesiveness is defined as the internal integrity of the sample and was calculated as the ratio of the second compression peak force area to the first compression peak force area. Springiness was calculated as the ratio of the second peak compression distance to the first peak compression distance. Gumminess was calculated as the product of hardness and cohesiveness and chewiness was the product of 


\section{Al Macrothink}

gumminess and springiness (Bhaktaraj, Prajapati, Nepal, Timalsina, \& Mitra, 2019; Bourne, 2002). Ten replications of each sample were performed, and the average value of each property was reported.

\subsection{Porosity-Rehydration Ratio Relationship and Power Law Modeling}

The relationship between porosity and rehydration ratio of horseradish samples dried 55, 65, 75,85 and $95^{\circ} \mathrm{C}$ was used to model using the following power law:

$$
R R=E \epsilon^{n}
$$

where, $\mathrm{RR}=$ Rehydration ratio $(\%), \epsilon=$ Porosity $(\%)$ and Constants $=\mathrm{E}$ and $\mathrm{n}$. The power law model was solved using the porosity-rehydration experimental data and determined the model parameters ( $E$ and $n$ ) to establish a mathematical relationship to predict the rehydration ratio as a function of porosity of the dried horseradish samples.

\subsection{Statistical Analysis}

The statistical analysis was performed using IBM SPSS software version 25 . The results of the physicochemical and textural properties of horseradish dried at $55,65,75,85$, and $95^{\circ} \mathrm{C}$ were reported as mean \pm standard deviation. One-way single factor Analysis of Variance (ANOVA) test was used for the analysis of physicochemical and textural properties of dried horseradish to determine significant effect of drying temperature on the quality of dried horseradish products at $p \leq 0.05$. In order to determine the differences among the results of the mean of the different dried horseradish samples Duncan Multiple Range Test (DMRT) was also performed.

\section{Results and Discussion}

\subsection{Effect Drying Temperature on the Physicochemical Properties of Dried Horseradish}

The horseradish was dried at $55,65,75,85$ and $95{ }^{\circ} \mathrm{C}$ until reaching to a constant weight and observed the effect of temperature on the physicochemical qualities (moisture content, water activity, bulk density, piece density, solid density, porosity, rehydration ratio, L value, a value and $b$ value) of the dried horseradish. The physicochemical properties of dried horseradish are presented in Table 1. The statistical analysis ANOVA (analysis of variance) was conducted to justify the significant effects of hot air-drying temperatures on the physicochemical properties of dried horseradish. A Duncan's Multiple Range Test (DMRT) was conducted because the ANOVA analysis cannot determine whether each individual mean is significantly different from all other means of the group. The DMRT and ANOVA results of the physicochemical properties of five different dried horseradish samples are presented in Table 1 and Table 2. The results indicated that drying temperature affected the quality of dried horseradish significantly $(\mathrm{p}<0.05)$. The detail results with discussion are presented below. 
Table 1. Effects of hot air thin layer drying temperatures on the physicochemical properties of dried horseradish

\begin{tabular}{llllll}
$\begin{array}{l}\text { Physicochemical } \\
\text { properties of dried } \\
\text { horseradish }\end{array}$ & 55 & 65 & 75 & 85 & 95 \\
\cline { 2 - 6 } & & \multicolumn{5}{c}{ Drying temperature $\left({ }^{\circ} \mathrm{C}\right)$} \\
\hline Moisture content $(\%)$ & $9.18^{\mathrm{c}} \pm 0.19$ & $8.43^{\mathrm{bc}} \pm 0.50$ & $7.70^{\mathrm{abc}} \pm 0.80$ & $7.17^{\mathrm{ab}} \pm 0.90$ & $6.15^{\mathrm{a}} \pm 0.37$ \\
Water activity $\left(\mathrm{a}_{\mathrm{w}}\right)$ & $0.06^{\mathrm{d}} \pm 0.19$ & $0.05^{\mathrm{bc}} \pm 0.01$ & $0.04^{\mathrm{ab}} \pm 0.01$ & $0.05^{\mathrm{cd}} \pm 0.00$ & $0.03^{\mathrm{a}} \pm 0.01$ \\
& & & & & \\
Bulk density $(\mathrm{g} / \mathrm{mL})$ & $0.27^{\mathrm{a}} \pm 0.00$ & $0.27^{\mathrm{a}} \pm 0.00$ & $0.28^{\mathrm{b}} \pm 0.00$ & $0.29^{\mathrm{c}} \pm 0.00$ & $0.3^{\mathrm{c}} \pm 0.00$ \\
& & & & & \\
Piece density $(\mathrm{g} / \mathrm{mL}))$ & $0.63^{\mathrm{a}} \pm 0.03$ & $0.66^{\mathrm{ab}} \pm 0.01$ & $0.70^{\mathrm{b}} \pm 0.03$ & $0.75^{\mathrm{c}} \pm 0.03$ & $0.84^{\mathrm{d}} \pm 0.01$ \\
Solid density $(\mathrm{g} / \mathrm{mL}))$ & $0.91^{\mathrm{a}} \pm 0.04$ & $0.92^{\mathrm{a}} \pm 0.02$ & $0.92^{\mathrm{a}} \pm 0.02$ & $0.94^{\mathrm{a}} \pm 0.03$ & $0.95^{\mathrm{a}} \pm 0.00$ \\
\hline
\end{tabular}

Means within a row with different letters are significantly different $(\mathrm{p}<0.05)$.

\subsection{Moisture Content and Water Activity of Dried Horseradish}

The results revealed that the final moisture content of dried horseradish decreased from 9.18 to $6.15 \%$ (wb) and the water activity of dried horseradish decreased from 0.06 to 0.03 with increased drying temperature from 55 to $95^{\circ} \mathrm{C}$ (Table 1). The one-way single factor ANOVA (Table 2) indicated that the $\mathrm{p}$ value for the moisture content and water activity of dried horseradish was smaller than 0.05 . The lower $\mathrm{p}$ value indicated the more significant difference between the drying temperatures. The $\mathrm{F}$ value was greater than $\mathrm{F}$ value at a critical point (Fcrit) for the moisture content and water activity of dried horseradish. The null hypothesis was rejected because of $F$ value $>$ Fcrit and this result indicated that the means of moisture content and water activity of dried horseradish were different, and the group means were not equal (Mason, Gunst, \& Hess, 2003; Mitra, Chang, \& Yoo, 2011; Mitra et al., 2013). The Duncan's Multiple Range Test (DMRT) was conducted to investigate whether each individual mean was significantly different from all the other means of the group or not. The DMRT results (Table 1) indicated that the moisture content and water activity of each dried horseradish were significantly different for all dried samples. The DMRT ranking of moisture content and water activity of dried horseradish samples in descending order was $55>65>75>85>95^{\circ} \mathrm{C}$ (Table 1). The results were in the agreement with the hot air drying of Thai garlic (Utama-ang, Cheewinworasak, Simawonthamgul, \& Samakradhamrongthai, 2018) and Galega kale (Oliveira, Ramos, Brandão, \& Silva, 2015). The relative humidity of air reduced and water holding capacity of air increased within the dryer with the dry bulb temperature, which increased the drying driving potential. At the constant air circulation (1.2 $\mathrm{m} / \mathrm{s}$ ), the higher drying temperature increased the drying rate by accelerating moisture diffusion from the horseradish (Babu et al., 2018; Mitra \& Meda, 2009). The faster 
movement of water from the center to the surface of sliced horseradish samples with the higher temperature might cause the higher shrinkage breaking more cell walls of horseradish samples. This phenomenon might remove more water from the samples with the higher temperature. This might be a reason that our dried horseradish samples retained the lowest moisture content at the highest drying temperature $\left(95^{\circ} \mathrm{C}\right)$ and the highest moisture content at the lowest drying temperature $\left(55^{\circ} \mathrm{C}\right)$. Although the degree of reduction of water activity $\left(\mathrm{a}_{\mathrm{w}}\right)$ of dried horseradish samples depended on the drying temperature the water activity of all five horseradish samples dried at 55-95 ${ }^{\circ} \mathrm{C}$ fell under 0.60 . The microbial growth on set water activity of any materials is 0.6 (Utama-ang et al., 2018). The results indicated that the water activity of dried horseradish samples (0.06-0.03) was very lower than the microbial growth on set water activity. Also, such lower water activity of any food products is desirable to prevent from the enzymatic/non-enzymatic reactions and lipid oxidation during storage (Babu et al., 2018). The results showed that all dried horseradish samples were shelf-stable dried products and could be supplied throughout the year.

Table 2. ANOVA results for the physicochemical properties of the dried horseradish

\begin{tabular}{|c|c|c|c|c|c|c|}
\hline $\begin{array}{l}\text { Physicochemical } \\
\text { properties of dried } \\
\text { horseradish }\end{array}$ & SS & $\mathrm{df}$ & MS & F value & Fcrit & p-value \\
\hline Moisture content (\%) & 10.76 & 4 & 2.69 & 7.17 & 5.19 & 0.027 \\
\hline Water activity $\left(\mathrm{a}_{\mathrm{w}}\right)$ & 0.001 & 4 & 0.000 & 13.94 & 3.48 & 0.000 \\
\hline Bulk density (g/mL) & 0.003 & 4 & 0.001 & 69.50 & 3.48 & 0.000 \\
\hline Piece density $(\mathrm{g} / \mathrm{mL}))$ & 0.081 & 4 & 0.020 & 38.20 & 3.48 & 0.000 \\
\hline Solid density $(\mathrm{g} / \mathrm{mL}))$ & 0.003 & 4 & 0.001 & 1.39 & 3.48 & 0.307 \\
\hline Porosity (\%) & 653.41 & 4 & 163.35 & 11.46 & 3.48 & 0.001 \\
\hline Rehydration ratio (\%) & 1653.47 & 4 & 413.37 & 17.46 & 5.19 & 0.004 \\
\hline L-value & 413.08 & 4 & 103.27 & 9.96 & 2.76 & 0.000 \\
\hline \multirow[b]{2}{*}{ b-value } & 26.38 & 4 & 6.60 & 11.99 & 2.76 & 0.000 \\
\hline & 145.75 & 4 & 36.44 & 11.54 & 2.76 & 0.000 \\
\hline
\end{tabular}




\section{Macrothink}

\subsection{Densities of Dried Horseradish}

The density of a product is mass/volume. Depending on the methods (as described in the method section) to determine the volume of a certain amount of a product, the density can be categorized as bulk density, piece density and solid density (Rodríguez-Ramírez, Méndez-Lagunas, López-Ortiz, \& Torres, 2012). The bulk density of the dried products is necessary for the packaging volume design (Roongruangsri \& Bronlund, 2016), whereas, piece density and solid density are related to textural properties, rehydration and porosity of the dried products (López-Ortiz, Rodríguez-Ramírez, \& Méndez-Lagunas, 2013; Rodríguez-Ramírez et al., 2012). The one-way single factor ANOVA as shown in Table 2 ( $>0.05$ and $F$ value $<$ Fcrit) indicated the drying temperature did not affect the solid density (Mason et al., 2003). Also, the DMRT analysis was not able to separate the mean from each other of the different horseradish dried samples. This might be the volume of dry horseradish powder was constant for a certain amount of dry horseradish powder for all tested drying temperatures. This result was in the agreement with a published review paper (Rodríguez-Ramírez et al., 2012). The one-way single factor ANOVA showed that the drying temperature affected the bulk density and piece density significantly as shown in Table 2 ( $\mathrm{p}<0.05$ and $\mathrm{F}$ value $>$ Fcri). The DMRT ranking of bulk density of dried horseradish samples in ascending order was $55 \& 58>75>85 \& 95{ }^{\circ} \mathrm{C}$ (Table 1), whereas, the DMRT ranking of piece density of dried horseradish samples in ascending order was $55 \& 65>65 \&$ $75>>85>95{ }^{\circ} \mathrm{C}$ (Table 1). The results indicated that the bulk density of dried horseradish samples was lower than the piece density of the dried horseradish samples. The results were expected because bulk density was calculated using bulk volume (product volume + pore space volume + volume of space between dried horseradish slices), whereas, piece density was calculated using piece volume (product volume + pore space volume). The bulk density of dried horseradish samples increased from 0.27 to $0.30 \mathrm{~g} / \mathrm{mL}$ when the drying temperature increased from 55 to $95{ }^{\circ} \mathrm{C}$ (Table 1). The results indicated the bulk volume of dried horseradish increased with the decreased drying temperature. Our study suggested that the higher packaging space for the dried horseradish was required when horseradish was dried with a lower temperature. The piece density of dried horseradish samples increased from 0.63 to $0.84 \mathrm{~g} / \mathrm{mL}$ with the increased drying temperature from 55 to $95{ }^{\circ} \mathrm{C}$ (Table 1). The trend of piece density results was opposite of a study of the drying temperature effects on the density of dried garlic (López-Ortiz et al., 2013). But our study was in the agreement with a study of pumpkin drying temperature (Roongruangsri \& Bronlund, 2016). Our study indicated that the piece density of dried materials depended on the destruction kinetics of cell walls during drying process. Our results indicated that the higher drying temperature destroyed more cell walls of horseradish samples compared to lower drying temperature, hence, the higher drying temperature increased the densification of the dried horseradish samples by decreasing porous structure (porosity) and increasing compaction forces of dried horseradish samples. A study with Saskatoon berry drying showed that the higher heat during drying caused more microstructural destruction (Nagalakshmi et al., 2014). Our porosity results (Figure 2) and hardness results (Table 2) confirmed this phenomenon. This phenomenon might cause the higher piece density of dried horseradish samples with the higher drying temperature. 


\section{Macrothink}
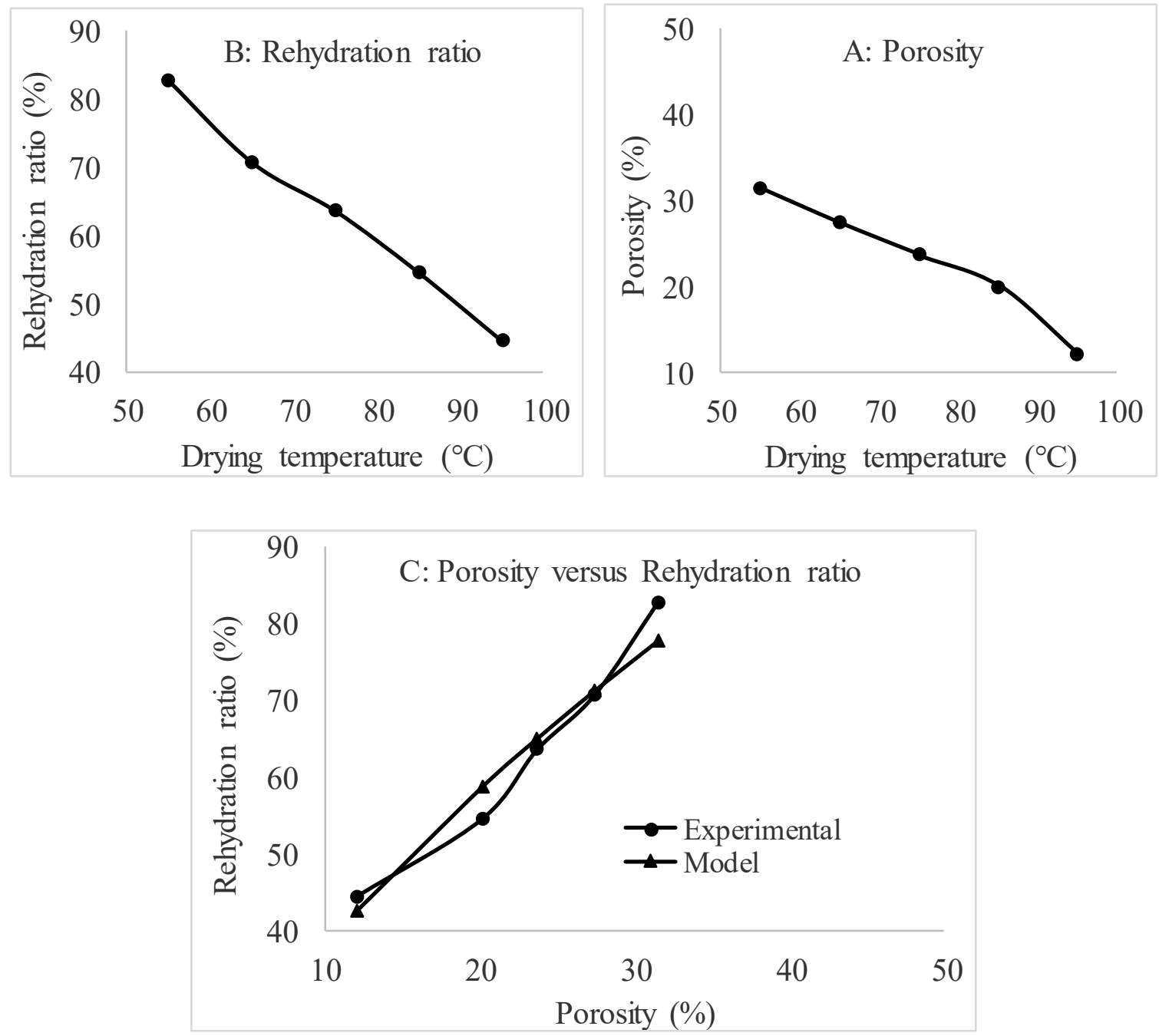

Figure 2. Effects hot air-drying temperature on porosity (A), rehydration ratio (B) and experimental and power law model relationship between porosity and rehydration ratio of dried horseradish samples $(\mathrm{C})$

\subsection{Porosity, Rehydration Ratio and Power Law Modeling of Dried Horseradish}

The porosity and rehydration of the dried products determine the intensity of the damage of structures of the materials during drying process. Porosity is related to solid density and piece density and determined the porous status of the dried products. The rehydration ratio determines the induced damages in the material during drying (Babu et al., 2018; Horuz, Bozkurt, Karataş, \& Maskan, 2018; Vega-Gálvez et al., 2009). The effects of hot air-drying temperatures on the porosity and rehydration ratio of the dried horseradish samples are shown in Figure 2 (A) and Figure 2 (B), respectively. The both (experimental and power law model) relationships between porosity and rehydration ratio of dried horseradish samples are shown in Figure 2 (C). The porosity results indicated the drying temperature had a significant effect on the porosity $(p<0.05)$. The porosity $(31.47-12.13 \%)$ of dried horseradish samples decreased with the increased drying temperature. Since solid density of dried horseradish 


\section{MInstitute ${ }^{\text {Mink }}$}

samples was not affected by the drying temperature significantly the piece density influenced the porosity of the dried horseradish samples. The denser dried products possess lesser porosity (Lewicki \& Jakubczyk, 2004; López-Ortiz et al., 2013). Our study indicated that the dried horseradish samples became denser with higher drying temperature. This phenomenon caused an inverse relationship between drying temperature and porosity of dried horseradish samples. The rehydration study indicated that the rehydration ratio of dried horseradish was inversely related to the drying temperature. There was a significant effect of drying temperature on the rehydration ratio of the dried horseradish samples $(p<0.05)$. The rehydration ratio (82.74-44.47\%) of dried horseradish samples decreased with the increased drying temperature. The higher drying temperature might break the higher amounts of cells and damage the internal structures of the horseradish samples during drying (Horuz et al., 2018; Lewicki \& Jakubczyk, 2004). The damaged broken cells with the higher drying temperature might be compacted in the dried products which reduced the water absorption capacity of the dried horseradish samples. The results as shown in Figure 2 (C) revealed that the porosity of the dried horseradish samples was linearly related to the rehydration ratio of the dried horseradish samples. The increased porosity increased the rehydration ratio of the dried horseradish samples. This result was supported by other studies (Horuz et al., 2018; Lewicki \& Jakubczyk, 2004; López-Ortiz et al., 2013; Vega-Gálvez et al., 2009). The power law solutions $E(8.83)$ and $n(0.63)$ were very effective to predict rehydration ratio of the dried horseradish samples with an accuracy of $95 \%\left(\mathrm{R}^{2}=0.95\right)$. The power law model as shown in Figure 2 (C) indicated the experimental relationship between porosity and rehydration ratio of dried horseradish samples could be represented by the power law model. The power law modeling results indicated the model solutions were potentially useful to establish the correlation between porosity and rehydration ratio of dried horseradish samples.

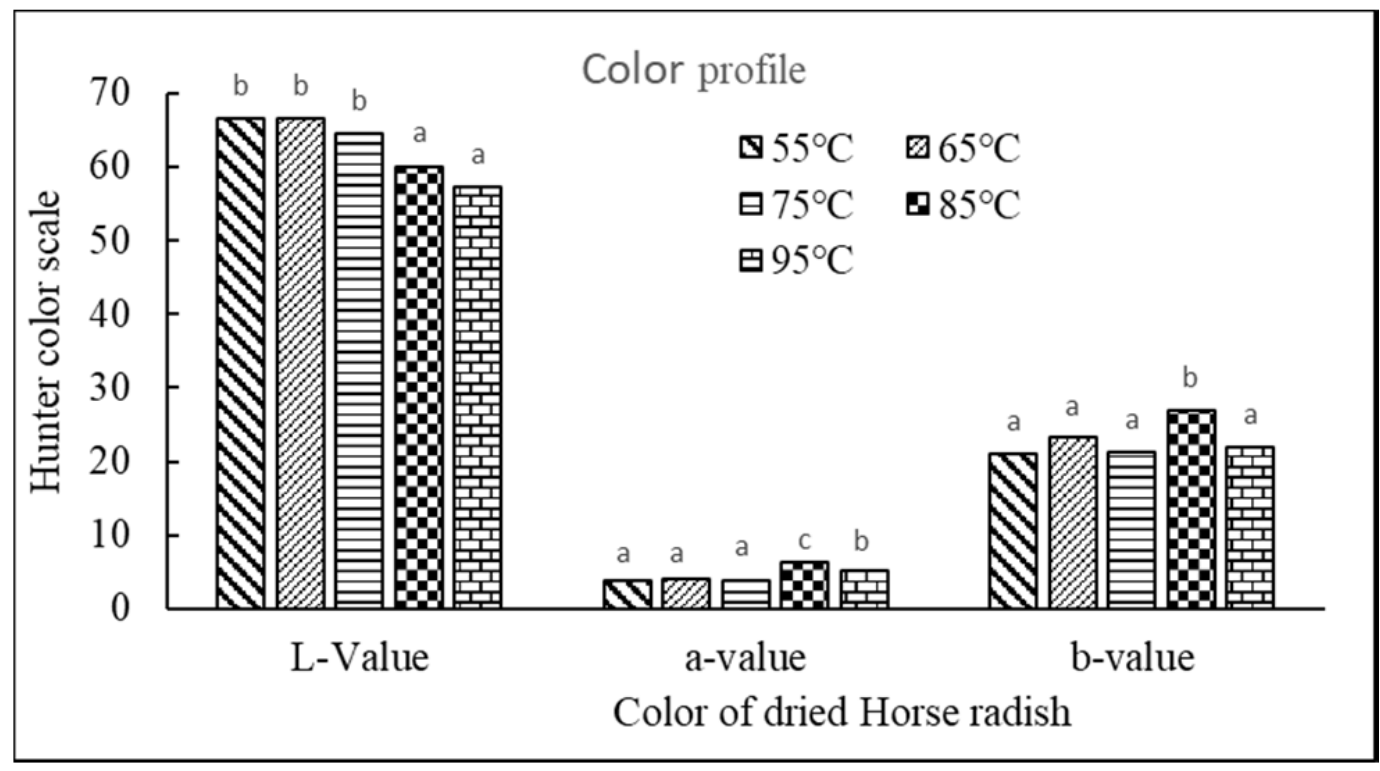

Figure 3. Effects of hot air-drying temperatures on the L-value, a-value and b-value of the dried horseradish samples

Means within a column with different letters are significantly different $(p<0.05)$ 


\section{MInstitute Macrothink $^{m}$}

\subsection{Color of Dried Horseradish}

The color of any food products is a very important property which can influence consumers' acceptance of the products and can be correlated with the product shelf-life (Roongruangsri $\&$ Bronlund, 2016). The hunter color coordinates of $L$ value ( 0 for complete black/dark and 100 for complete white/lightness), a value ( + a for redness and $-\mathrm{a}$ for greenness) and $\mathrm{b}$ value ( $+\mathrm{b}$ for yellowness and -b for blueness) were determined (Oliveira et al., 2015; Vega-Gálvez et al., 2009). The L value, a value and b value of the horseradish samples dried at 55, 65, 75, 85 and $95{ }^{\circ} \mathrm{C}$ are shown in Figure 3. The $\mathrm{L}$ value, a value and $\mathrm{b}$ value of fresh horseradish slices were $71.21,2.23$ and 20.51, respectively. The ANOVA $(p<0.05$ and $F$ value $>$ Fcrit, Table 3) showed the drying temperature affected the color profiles of dried horseradish samples significantly. The DMRT analysis was not able to find any difference for the temperature of $55-75^{\circ} \mathrm{C}$ but was able to separate means between $55-75{ }^{\circ} \mathrm{C}$ and $85-95{ }^{\circ} \mathrm{C}$ for the $\mathrm{L}$ value, $a$ value and $b$ value of dried horseradish samples (Figure 3 ). The color results (Figure 3 ) indicated that the $L$ value of dried samples decreased and, a value and $b$ value of dried samples increased for all drying temperatures compared to fresh horseradish. However, the degree of change of the color profile of dried horseradish samples depended on the drying temperature. Depending on the drying temperature, the results indicated that the $\mathrm{L}$ value of dried samples decreased from 6.60 to $19.67 \%$, a value (redness) of dried samples increased from 69.51 to $180.82 \%$ and $b$ value (yellowness) of dried samples increased from 2.54 to $31.53 \%$ of initial (fresh horseradish) color profile. The L value of dried horseradish samples increased from 57.20 to 66.51 when the drying temperature decreased from 95 to $55^{\circ} \mathrm{C}$. The results confirmed that the dried horseradish samples became darker with the drying temperature (Figure 1 and Figure 3). The lower drying temperature increased the water content of dried horseradish samples and this increased water content of dried samples increased the lightness ( $\mathrm{L}$ value) with lower temperature. There is a hypothesis that a food with a higher water content may possess a higher L value (lightness) (Vega-Gálvez et al., 2009). Our L value results of the dried horseradish samples were supported by the L value results of a study on Galega kale dried products (Oliveira et al., 2015). The redness (+ a value) of dried horseradish samples increased with drying temperature. The high drying temperature in exposure with oxygen might alter the phenolic compounds and glycosylates of horseradish through enzymatic and non-enzymatic reactions (Oliveira et al., 2015; Vega-Gálvez et al., 2009) and this phenomenon might cause the increase the redness of dried samples with the higher drying temperature. The yellowness $(+b$ value) of dried horseradish samples increased with the drying temperature. This phenomenon may be justified by the development of brown products during drying at a high temperature due to the Maillard reaction (Vega-Gálvez et al., 2009). Our results are in the agreement with other studies (Oliveira et al., 2015; Roongruangsri \& Bronlund, 2016; Utama-ang et al., 2018). 


\section{IIacrothink}

Table 3. Effects of hot air thin layer drying temperatures on the textural properties of dried horseradish

\begin{tabular}{|c|c|c|c|c|c|}
\hline \multirow{2}{*}{$\begin{array}{l}\text { Textural } \\
\text { profile } \\
\text { dried } \\
\text { horseradish }\end{array}$} & \multicolumn{5}{|c|}{ Drying temperature $\left({ }^{\circ} \mathrm{C}\right)$} \\
\hline & 55 & 65 & 75 & 85 & 95 \\
\hline Hardness $(\mathrm{N})$ & $193.63^{\mathrm{a}} \pm 37.16$ & $197.29^{\mathrm{a}} \pm 7.88$ & $214.05^{\mathrm{a}} \pm 46.67$ & $277.53^{b} \pm 48.03$ & $298.31^{\mathrm{b}} \pm 40.46$ \\
\hline Cohesiveness & $1.04^{\mathrm{a}} \pm 0.10$ & $1.08^{\mathrm{a}} \pm 0.16$ & $1.03^{\mathrm{a}} \pm 0.08$ & $1.06^{\mathrm{a}} \pm 0.13$ & $1.32^{\mathrm{a}} \pm 0.22$ \\
\hline Springiness & $3.14^{\mathrm{a}} \pm 0.01$ & $3.14^{\mathrm{a}} \pm 0.00$ & $3.13^{\mathrm{a}} \pm 0.00$ & $3.13^{\mathrm{a}} \pm 0.01$ & $3.13^{\mathrm{a}} \pm 0.01$ \\
\hline Gumminess & $202.16^{\mathrm{a}} \pm 49.47$ & $213.09^{\mathrm{a}} \pm 35.41$ & $224.32^{\mathrm{a}} \pm 69.18$ & $294.68^{b} \pm 59.08$ & $390.12^{b} \pm 44.41$ \\
\hline Chewiness & $635.08^{a} \pm 154.55$ & $669.26^{\mathrm{a}} \pm 111.73$ & $704.22^{\mathrm{a}} \pm 217.21$ & $924.97^{b} \pm 185.50$ & $1223.55^{\mathrm{b}} \pm 138.45$ \\
\hline
\end{tabular}

Means within a row with different letters are significantly different $(\mathrm{p}<0.05)$.

Table 4. ANOVA results for the textural properties of the dried horseradish

\begin{tabular}{lllllll}
\hline Textural properties & SS & df & MS & F value & Fcrit & p-value \\
\hline Hardness (N) & 44572.64 & 4 & 11143.16 & 7.04 & 2.90 & 0.001 \\
Cohesiveness & 0.120 & 4 & 0.030 & 1.13 & 2.90 & 0.373 \\
Springiness & 0.000 & 4 & 0.000 & 0.84 & 2.90 & 0.515 \\
Gumminess & 100562.50 & 4 & 25140.62 & 7.71 & 2.90 & 0.001 \\
Chewiness & 987041.70 & 4 & 246760.24 & 7.71 & 2.90 & 0.001 \\
\hline
\end{tabular}

\subsection{Effect Drying Temperature on the Textural Properties of Dried Horseradish}

The textural/mechanical (hardness, cohesiveness, springiness, gumminess and chewiness) properties of any food products are very important because these properties are correlated to the sensorial acceptance of products and the mechanical quality characterization of products. The textural properties of horseradish samples dried at 55, 65, 75, 85 and $95^{\circ} \mathrm{C}$ and the DMRT results of the textural properties of dried horseradish samples are presented in Table 3. The one-way single factor ANOVA results of the textural properties of dried horseradish samples are presented in Table 4. The ANOVA results indicated that the drying temperature 


\section{MInstitute ${ }^{\text {Mink }}$}

affected the hardness, gumminess and chewiness of the dried horseradish samples significantly ( $\mathrm{p}<0.05$, Table 4$)$. The drying temperature did not affect the cohesiveness and springiness of the dried horseradish samples ( $p>0.05$, Table 4). Also, the DMRT analysis was not able to find any significant effects of drying temperature on cohesiveness and springiness of dried horseradish samples. However, the experimental results as shown in Table 3 revealed that the cohesiveness (1.04-1.32) of dried horseradish samples slightly increased and springiness (3.14-3.13) of dried horseradish samples slightly decreased with the drying temperature. This might be due to a change of final moisture content of dried samples and the alteration of cell membrane in the structure of the dried horseradish samples during drying (Bhaktaraj et al., 2019; Nagalakshmi et al., 2014). The hardness (193.63298.31 N), gumminess (202.13-39.12) and chewiness (635.08-1223.55) of dried horseradish samples increased with drying temperature (Table 3). This study indicated that the hardness of the horseradish samples was linearly related to the final moisture content and to the piece density of the dried horseradish samples. The higher drying temperature produced more dense dried horseradish samples with lower moisture content (Table 1), subsequently, increased the hardness of the dried horseradish samples. When the food materials are heating with hot air the internal stress is developed due to the moisture and temperature gradients. The faster the drying with higher temperature the larger the stresses (Lewicki \& Jakubczyk, 2004). The high stresses with the high drying temperature might cause the shrinkage, rapture/collapse of internals cells and compacted cells during horseradish drying (Horuz et al., 2018), therefore, the hard texture was formed. Another reason might be the increased accumulation of solutes with the increased drying temperature (Bhaktaraj et al., 2019; Horuz et al., 2018). The higher solutes provided the harder dry skin of the dried horseradish samples. Gumminess is the energy required to disintegrate a semisolid food to a state of readiness for swallowing and the gumminess (hardness $\times$ cohesiveness) is a function of hardness and cohesiveness. Chewiness is the energy required to masticate a solid food product and the chewiness is the function of (hardness $\times$ cohesiveness $\times$ springiness) gumminess and springiness (Bourne, 2002). Since our study indicated that drying temperature did not have a significant effect on the cohesiveness and springiness the hardness of the dried horseradish samples dominated the gumminess and chewiness of the dried horseradish samples. Therefore, the gumminess and chewiness followed the similar trend (increased with drying temperature) of hardness of dried horseradish samples. The gumminess and chewiness results indicated that the higher mastication energy was required when the horseradish was dried with the higher drying temperature.

\section{Conclusion}

The results indicated that the hot air thin layer drying method with relatively lower drying temperature was potential for the desired physicochemical and textural properties of dried horseradish samples. The statistical ANOVA analysis showed that the drying temperature affected the physicochemical and textural properties of dried horseradish samples significantly $(\mathrm{p}<0.05)$. The moisture content, $\mathrm{a}_{\mathrm{w}}$, porosity and rehydration ratio of dried horseradish samples decreased, and piece density, hardness, cohesiveness, gumminess and chewiness of dried horseradish samples increased with the drying temperature. Power law 


\section{Ml Macrothink}

modeling established a linear relationship between porosity and rehydration ratio of dried horseradish samples. The hot air-drying temperature between 55 and $65^{\circ} \mathrm{C}$ was suitable for the retention of physicochemical and textural properties dried horseradish samples. This hot air-drying method for the drying of horseradish can be economically viable and can be a suitable preservation method for the supplying horseradish throughout the year.

\section{Acknowledgements}

The research was funded by the University of Wisconsin-Stout Discovery Center Research Fellow grant. The horseradish bulk samples were donated by the Huntsinger Farms Inc., Eau Claire, WI, USA. We are thankful to Margaret Schultz for her help during lab work to collect data.

\section{References}

AACC. (2001). Approved Methods of Analysis. Method 10-05.01. Guidelines for Measurement of Volume by Rapeseed Displacement. https://doi.org/10.1094/AACCIntMethod-10-05.01

Agneta, R., Möllers, C., \& Rivelli, A. R. (2013). Horseradish (Armoracia rusticana), a neglected medical and condiment species with a relevant glucosinolate profile: A review. Genetic Resources and Crop Evolution, 60(7), 1923-1943. https://doi.org/10.1007/s10722-013-0010-4

Andruţa, M. E., Vlaic, R., Petruț, G., Chiș, S., \& Muste, S. (2017). Development and Characterization of a Biologically Active White Sauce Based on Horseradish, Onion, Parsley and Parsnip. Hop and Medicinal Plants, 27(1-2), 139-148.

Babu, A. K., Kumaresan, G., Raj, V. A. A., \& Velraj, R. (2018). Review of leaf drying: Mechanism and influencing parameters, drying methods, nutrient preservation, and mathematical models. Renewable and Sustainable Energy Reviews, 90, 536-556. https://doi.org/10.1016/j.rser.2018.04.002

Bhaktaraj, S., Prajapati, R., Nepal, K., Timalsina, P., \& Mitra, P. (2019). Effect of Sucrose Content ( ${ }^{\circ}$ brix) and Different Flavors on Physical, Mechanical and Sensorial Properties of Ginger Candy. Food Science and Nutrition Technology, 4(2), 1-11. https://doi.org/10.23880/fsnt-16000177

Bourne, M. C. (2002). Food texture and viscosity: concept and measurement. San Diego: Academic Press.

Horuz, E., Bozkurt, H., Karataş, H., \& Maskan, M. (2018). Comparison of quality, bioactive compounds, textural and sensorial properties of hybrid and convection-dried apricots. Journal of Food Measurement and Characterization, 12(1), 243-256. https://doi.org/10.1007/s11694-017-9635-x

Kumar, A. (2003). Software takes the sting out of horseradish production. Food Engineering, $75(4), 78$. 
Lewicki, P. P., \& Jakubczyk, E. (2004). Effect of hot air temperature on mechanical properties of dried apples. Journal of Food Engineering, 64(3), 307-314. https://doi.org/10.1016/j.jfoodeng.2003.10.014

Lin, C. M., Preston, J. F., \& Wei, C. I. (2000). Antibacterial mechanism of allyl isothiocyanate. Journal of Food Protection, 63(6), 727-734.

López-Ortiz, A., Rodríguez-Ramírez, J., \& Méndez-Lagunas, L. L. (2013). Effects of drying air temperature on the structural properties of garlic evaluated during drying. International Journal of Food Properties, 16(7), 1516-1529. https://doi.org/10.1080/10942912.2011.599090

Mason, R. L., Gunst, R. F., \& Hess, J. L. (2003). Statistical design and analysis of experiments: with applications to engineering and science (Vol. 474). John Wiley \& Sons.

Mitra, P., Chang, K. S., \& Yoo, D. S. (2011). Kaempferol Extraction from Cuscuta reflexa using Supercritical Carbon Dioxide and Separation of Kaempferol from the Extracts. In International Journal of Food Engineering 7(4), 1-15. https://doi.org/10.2202/1556-3758.1768

Mitra, P., \& Meda, V. (2009). Optimization of Microwave-Vacuum Drying Parameters of Saskatoon Berries Using Response Surface Methodology. Drying Technology, 27(10), 1089-1096. https://doi.org/10.1080/07373930903221101

Mitra, P., Meda, V., \& Green, R. (2013). Effect of drying techniques on the retention of antioxidant activities of Saskatoon berries. International Journal of Food Studies, 2, 224-237. https://doi.org/10.7455/ijfs/2.2.2013.a8

Nagalakshmi, S. A., Mitra, P., \& Meda, V. (2014). Color, Mechanical, and Microstructural Properties of Vacuum Assisted Microwave Dried Saskatoon Berries. International Journal of Food Properties, 17(10), 2142-2156.

Nguyen, N. M., Gonda, S., \& Vasas, G. (2013). A Review on the Phytochemical Composition and Potential Medicinal Uses of Horseradish (Armoracia rusticana) Root. Food Reviews International, 29(3), 261-275. https://doi.org/10.1080/87559129.2013.790047

Oliveira, S. M., Ramos, I. N., Brandão, T. R. S., \& Silva, C. L. M. (2015). Effect of Air-Drying Temperature on the Quality and Bioactive Characteristics of Dried Galega Kale (Brassica oleraceaL. var. Acephala). Journal of Food Processing and Preservation, 39(6), 2485-2496. https://doi.org/10.1111/jfpp.12498

Rodríguez-Ramírez, J., Méndez-Lagunas, L., López-Ortiz, A., \& Torres, S. S. (2012). True Density and Apparent Density During the Drying Process for Vegetables and Fruits: A Review. Journal of Food Science, 77(12), 145-154. https://doi.org/10.1111/j.1750-3841.2012.02990.x

Roongruangsri, W., \& Bronlund, J. E. (2016). Effect of air-drying temperature on physico-chemical, powder properties and sorption characteristics of pumpkin powders. International Food Research Journal, 23(3), 962-972. 


\section{Macrothink}

Journal of Food Industry

ISSN 1948-545X 2019, Vol. 3, No. 1

Shende, D., \& Datta, A. K. (2019). Refractance window drying of fruits and vegetables: a review. Journal of the Science of Food and Agriculture, 99(4), 1449-1456. https://doi.org/10.1002/jsfa.9356

Utama-ang, N., Cheewinworasak, T., Simawonthamgul, N., \& Samakradhamrongthai, R. S. (2018). Effect of drying condition of Thai garlic (Allium sativum L.) on physicochemical and sensory properties. International Food Research Journal, 25(4), 1365-1372.

Vega-Gálvez, A., Di Scala, K., Rodríguez, K., Lemus-Mondaca, R., Miranda, M., López, J., \& Perez-Won, M. (2009). Effect of air-drying temperature on physico-chemical properties, antioxidant capacity, colour and total phenolic content of red pepper (Capsicum annuum, L. var. Hungarian). Food Chemistry, 117(4), 647-653. https://doi.org/10.1016/j.foodchem.2009.04.066

\section{Copyright Disclaimer}

Copyright for this article is retained by the author(s), with first publication rights granted to the journal.

This is an open-access article distributed under the terms and conditions of the Creative Commons Attribution license (http://creativecommons.org/licenses/by/4.0/). 